\title{
Tierras indígenas y servicios militares en la frontera sur de Cuyo, siglos XVII-XIX
}

Diego Escolar

\section{Resumen}

Este trabajo analiza cómo los indígenas del centro de Cuyo obtuvieron y defendieron el reconocimiento de tierras y liderazgos en las lagunas de Guanacache y Corocorto desde fines del siglo XVII hasta principios del XIX. La hipótesis principal es que la necesidad de los españoles de proteger la frontera con pueblos mapuche abrió un espacio para la obtención de esos derechos para los indios tempranamente colonizados al interior del territorio de dominio colonial, a cambio de su presencia militar defensiva y servicios militares en la frontera.

Palabras clave: Tierras huarpes y puelches - Servicios militares - Frontera mapuche

\section{Summary}

This work analyzes how the indigenous people of the center of Cuyo obtained recognition of lands and leadership in Corocorto and the Guanacache lagoons from the late seventeenth to the early nineteenth centuries. The hypothesis is that the need of the Spaniards to protect the Mapuche border opened a space to obtain these rights for the early colonized Indians within the territory of colonial rule in exchange for their defensive military presence and military services on the border.

Keywords: Huarpes's and puelches's lands - Military services - Mapuche frontier

La región de Cuyo, hoy perteneciente a la Argentina y hasta 1776 dependiente de la capitanía de Chile, ${ }^{1}$ presentó durante mucho tiempo una doble frontera de guerra

\footnotetext{
* Universidad Nacional de Cuyo. CONICET. E mail: descolar@gmail.com

1 Los actuales valles centrales de Mendoza y San Juan fueron colonizados desde Chile con la fundación de las ciudades de Mendoza (1561) y San Juan de la Frontera (1562). La región perteneció a la capitanía de Chile hasta 1776 cuando pasó a formar parte del virreinato del Río de la Plata.
} 
entre los colonos españoles y, por un lado, los grupos denominados genéricamente capayanes o diaguitas, al norte, como por el otro con pueblos posteriormente incluidos en el "mundo mapuche", puelches, pehuenches, pampas o aucas, en el sur. ${ }^{2}$ El primer frente estuvo activo hasta la represión del denominado Gran Alzamiento calchaquí de 1632, al cual se plegaron los diaguitas sanjuaninos. Las parcialidades puelches y pehuenches del sur de Mendoza, en cambio, vivieron un proceso mucho más paulatino de conquista con avances y retrocesos hasta fines del siglo XIX cuando las campañas militares llevadas a cabo por el estado argentino entre 1878 y 1884 conquistaron definitivamente su territorio. Mientras tanto, el centro de colonización temprana de la región desde mediados del siglo XVI con las fundaciones de las ciudades de Mendoza y San Juan, estaba poblada por los denominados huarpes. Estos fueron gravemente afectados desde fines del siglo y a lo largo del XVII por levas masivas a Santiago y otras áreas del valle Central y el Norte Chico chilenos ${ }^{3}$ circunstancia que alimentó la narrativa de su masiva extinción. ${ }^{4}$ Sin embargo, la extinción no fue tal sino que muchos huarpes continuaron habitando en estancias y parajes originales, huyeron a lugares inaccesibles o donde podían obtener refugio, como las Lagunas de Guanacache o la frontera sur, o retornaban de Chile.

Debido a la idea de la desaparición de los huarpes junto con una secular tendencia de negar la presencia indígena en la región, ${ }^{5}$ la existencia de tierras reconocidas a los indios en el centro de Cuyo hasta el siglo XIX es desconocida en general por el público y ha sido muy poco tratada por la historiografía local. Menos aún sus circunstancias, es decir cómo pudieron parcialidades o comunidades indígenas teóricamente inexistentes, desestructuradas o asimiladas, mantener la ocupación y

2 Estas clasificaciones son relativas porque existieron intercambios poblacionales y culturales de diversa índole y en distintos contextos entre los grupos. En las diásporas y desplazamientos forzados, en Cuyo, Chile y otras áreas del este como Córdoba y Buenos Aires, y en la misma frontera. Y también porque siguiendo a las teorías interaccionistas de la etnicidad y su contraparte bourdieana, estas clasificaciones eran mutuamente articuladas en las mismas relaciones y también por parte de los colonizadores. La bibliografía al respecto es muy vasta con diferencias que en este momento no son relevantes para nuestro análisis. Para el contexto argentino podemos mencionar los aportes de Lidia Nacuzzi (1998), sobre los pampas, aucas y otros del área pampeana y de Christophe Giudicelli (2011) para los calchaquíes en el Tucumán colonial. Para los reche-mapuche de Chile el de Guillaume Boccara (2007). En cuanto a las bases teóricas principales citaremos a Barth (1976) y Pierre Bourdieu con su concepto de "luchas de clasificación". Una aplicación influyente de este último enfoque fuera del contexto americano es la de Jean-Loupe Amselle (1998).

3 Verdaguer, 1931, Jara, 1958, Prieto, 2000.

4 Canals Frau, 1946, Michieli, 1983, Prieto, 1976, entre otros.

5 Escolar, 2007. 
status legal de sus tierras en una época tan tardía para lo habitualmente considerado, que se enlaza en la práctica con el período independentista.

En este artículo abordaré la historia de las tierras indígenas del centro de Cuyo, elaborando una hipótesis: que una de las principales razones por las que parcialidades del área considerada huarpe de las Lagunas de Guanacache y Corocorto pudieron acceder y mantener en el tiempo sus tierras fue su importancia estratégica como fuerza militar y de contención en la frontera sur contra los puelches, pehuenches, huilliches, pampas y más tarde ranqueles. Las necesidades militares de los enclaves coloniales cuyanos contra la persistente resistencia indígena, que en algunas épocas como la segunda mitad del siglo XVII recuperó áreas previamente ocupadas o controladas por los españoles (los valles de Uco y Jaurúa en Mendoza) obligó a los españoles a negociar con los laguneros y puelches (chiquillanes, morcoyanes, tunuyanes y otros). Estas negociaciones implicaron, como he analizado para el caso de Mogna en San Juan ${ }^{6}$ tanto el reconocimiento de tierras y cargos de caciques como la formas y lugares en que se fundaron pueblos de indios y villas de españoles en el siglo XVIII. Así, a partir de algunos documentos poco conocidos y la lectura crítica de bibliografía precedente reconstruiré parte de las luchas, negociaciones y conflictos por las tierras indígenas y su relación con el contexto geopolítico regional en que se insertaron.

En el juicio seguido por el terrateniente Asencio Balmaceda en 1763 contra el cacique Francisco Alcani de Mogna, este se quejaba a través del protector de su aprisionamiento y el posterior secuestro de sus dos hijos, dos chinitas y "un gueñicito de menor edad". Gueñi es un término del mapuzungun o lengua mapuche por "muchacho", que me sorprendió encontrar en el testimonio escrito - el cual parece haber reproducido el discurso literal - de un cacique "diaguita" (muy lejos de los territorios de los indígenas que hablaban, mediados por el área tradicional de los huarpes, es decir Guanacache y los valles centrales cuyanos). Luego pensé que el uso del término podría deberse a los frecuentes viajes a Chile por parte del cacique, cuando acudía a la Real Audiencia en Santiago, como se desprende de algunos juicios que hemos analizado. También quizá a un pasado remoto de traslado forzoso

6 Escolar, 2020b.

7 Archivo Nacional de Chile (en adelante ANC), Capitanía General, vol. 522 f. 229. 
trasandino de su linaje en la época de las grandes levas a Chile durante el siglo XVII. En otro litigio de 1737 encontré un indicio que me pareció más plausible para explicar el préstamo lingüístico en mapuzungun. En un juicio para demostrar los derechos de Francisco Alcani al cacicazgo y las tierras de Mogna el protector citó un testigo que mencionó que, a principios del siglo, se habría expedido una real provisión sobre las tierras en favor de Diego Alcani, el abuelo de Francisco. ${ }^{8}$ Y que su padre Santiago Alcani había sido nombrado capitán por el corregidor para reclutar indios y formar compañías militares con el fin de defender la frontera de Cuyo contra la amenaza de indios alzados. ${ }^{9}$

Me pareció bastante plausible que las relaciones de indígenas del centro y norte de Cuyo con los grupos de habla mapuche en la frontera sur hubiera sido realmente significativa a partir de una experiencia militar y de intercambio con mapuche hablantes tanto "alzados" como reducidos. Y que esta participación, efectivamente, hubiera sido la llave para obtener el reconocimiento de las tierras para el grupo o para su linaje. Sin embargo, en las jurisdicciones próximas donde la etnohistoria o historia indígena ha tenido más desarrollo, como la Rioja, Tucumán y el norte argentino, no se había observado esta modalidad de derechos de acceso a la tierra para los indios por lo que parecía una situación bastante anómala. A excepción tal vez de lo señalado por Farberman para Santiago del Estero, donde hubo una política establecida de colocar pueblos de indios con fines militares en la frontera con los guaycurúes y abipones, ${ }^{10}$ esta situación marcaría una particularidad regional en las formas de acceso a la tierra por parte de los indígenas si lo comparamos con sus vecinos del Tucumán colonial y Córdoba.

Más allá de los indicios señalados para Mogna, durante los procesos fundacionales de pueblos de indios y villas que ocurrieron durante el siglo XVIII en las lagunas de Guanacache, en el centro, y en Corocorto, al sur, la relación entre el reconocimiento de derechos a la tierra a los indígenas del interior colonial y la dinámica fronteriza se observa con mucha más claridad. Por ello, en este artículo me centraré en la historia de las tierras y liderazgos indígenas en Mendoza durante el siglo XVIII, destacando la

8 Archivo Histórico de San Juan (en adelante AHSJ), caja 4, carp. 22, doc. 12, f. 1-28.

9 Michieli, 2000: 36.

10 Farberman, 2014: 36-37. 
geopolítica de la frontera del sur de Cuyo en la adjudicación de tierras y la capacidad de los actores para mantenerlas y sostener su poder relativo en las lagunas hasta fines del período colonial. Se trata del actual norte y centro de Mendoza, desde Guanacache hasta el río Tunuyán, donde se fundaron pueblos y villas también durante el siglo XVIII.

\section{Frontera mapuche y procesos reduccionales}

Durante el período colonial la tierra era otorgada a través de mercedes reales por parte de la corona o sus representantes políticos a los conquistadores como compensación por servicios prestados a la corona, fundamentalmente militares. También se reconocía en muchos casos la propiedad común de las tierras asignadas a los indígenas en tanto reducciones o pueblos de indios. Sin embargo, pese a algunas menciones esporádicas o circunstanciales, la propiedad de tierras de los indios no ha sido estudiada en profundidad por la historiografía regional, ni mucho menos el reconocimiento de estas o de cargos de caciques, también por servicios militares prestados a la corona. ${ }^{11}$ Hacia fines del siglo XVII y durante el XVIII se acrecentó notablemente la concesión de patentes militares a españoles cuando se otorgó esta prerrogativa a los corregidores. ${ }^{12}$ En su interpretación los nombramientos se habrían producido esencialmente por el interés de los actores en el prestigio social que conllevaban o respondiendo a estrategias clientelares de los corregidores, más que por una real actuación en la guerra. Cueto refuerza esta idea señalando que las mercedes como premios por servicios militares a la corona se otorgaban a españoles y muy difícilmente a miembros de otras naciones. ${ }^{13}$ No obstante ello, encontramos en Cuyo casos de reconocimiento de cargos de caciques y tierras entre los indígenas en función de su rol militar, aunque no se ha profundizado el estudio de estas prácticas. Inclusive, la ocupación de estas tierras se mantuvo en parte hasta fines del

11 Adolfo Omar Cueto menciona por ejemplo que existe documentación con reconocimientos sobre títulos legítimos de los nativos, compensaciones, solicitudes de amparo y procesos de defensa y ventas. Sin embargo, no proporciona las referencias de archivo sobre tales fuentes, exceptuando el caso de una defensa del protector de indios sobre las tierras de los indios de Corocorto en 1807 sobre la que volveremos, Cueto, 1998: 104.

12 Prieto, 2000: 220-221.

13 Cueto, 1989: 93. 
período colonial y en todos los casos que hemos podido comprobar la corona los reconoció posteriormente sobre la base de esos derechos originales.

Aunque la conquista de Cuyo comenzó en el siglo XVI los datos más antiguos sobre fundaciones de pueblos de indios son de 1664, cuando el Oidor de la Audiencia de Chile Don Gaspar Cuba y Arce cruzó la cordillera y permaneció varios meses en Mendoza con la misión de reducir a los indios a pueblo. ${ }^{14}$ Estos intentos se produjeron en el área de Guanacache, el río Tunuyán y el río Diamante. Corocorto, cercana a la desembocadura del Tunuyán en el Desaguadero, fue uno de los primeros parajes poblados que se mencionan. Ubicada hacia el sur de las lagunas de Guanacache, constituía parte de lo que Prieto denominó una "zona fronteriza de amortiguación" de los enclaves de dominio español con los pueblos indígenas libres del sur y del oriente. ${ }^{15}$ Aguas arriba del río Tunuyán, en el actual paraje denominado Reducción del departamento mendocino de Rivadavia, Cuba y Arce también fundó un pueblo que reunió puelches de Corocorto, Diamante y Cerro Nevado. ${ }^{16}$

Fernando Morales Guiñazú mencionó haber hallado escrituras de las postrimerías del siglo XVII en los valles de Uco y Jaurúa cercanos a Mendoza en los cuales figuraban indígenas como propietarios antecedentes. ${ }^{17}$ Aunque tampoco proporcionó fuentes, describió algunos casos a principios de la década de 1720 como el del cacique Fernando Caquiz (o Capiz) "poseedor y legítimo dueño" de unas tierras junto a la desembocadura del río Tunuyán y Pablo Pasambay o Pasambayan de una reducción "del otro lado del río Tunuyán" y también dueño de sus tierras. ${ }^{18}$ Los derechos serían ratificados a sus descendientes en la segunda mitad del siglo XVIII. ${ }^{19}$

La época en la cual según Morales Guiñazú algunas fuentes señalan propiedades asignadas a o representadas en caciques indígenas en el bajo Tunuyán no parece

14 AGI, Escribanía 939 A. Residencia de Gaspar Cuba y Arce como Oidor y Alcalde de Corte de la Audiencia de Chile. Año 1672.

15 Prieto, 2000: 213.

16 Prieto, 2000: 213.

17 Morales Guiñazú, 1938: 34.

18 Morales Guiñazú, 1938: 15.

19 Archivo Histórico de Mendoza (en adelante AHM), carp. 157, doc. 16. En 1759 los herederos de Caquis reclamaron al Corregidor de Cuyo Don Félix Joseph de Billalobos amparo por dos leguas de tierra sobre la costa del río Tunuyán que luego de haber exhibido títulos y levantado una información de testigos calificados obtuvo sentencia favorable de la Real Audiencia de Chile. 
fortuita, sino que coincide con un momento significativo de los conflictos en las relaciones hispano-indígenas en la frontera sur.

En un juicio por la sucesión del cacicazgo de una encomienda en las Lagunas de Guanacache, los caciques Talquinca de las lagunas de Guanacache - en el centro de Cuyo - defendían su legitimidad en contra de los Cunampa, entre otras cosas por su participación en la guerra contra los indígenas del sur. El cacique Bartolomé Talquinca había sido reducido con su gente en las Lagunas por el Oidor Don Gaspar Cuba y Arce. Los descendientes de su linaje argumentaban que habían servido "con armas como tales caciques, en las entradas del enemigo". El sargento mayor del batallón de Mendoza, por su parte, testificaba que Juan Talquinca

...ha acudido en toda ocasión contra el enemigo especialmente cuando en tiempos del corregidor Don Antonio de Catabajal se redujo a Don Lorenzo Chiquillán y recorrió toda la tierra hasta el Río Latuer y bajo el Gobernador D. Bernardo Cruzat fue [...] a la ciudad de Santiago en el invierno para llevar pliegos de importancia ${ }^{20}$

En diversos documentos vemos que caciques huarpes y puelches tienen reconocidos cargos y tierras en Corocorto y las Lagunas en función de su participación en la reducción de los chiquillanes. En 1704 se menciona al cacique Sebastián Paucán “que asiste en Corocorto desde el alzamiento de Don Lorenzo Chiquillan". ${ }^{21}$ En 1723 los caciques Don Melchor Tunuyán y Don Diego Seme o Semeyan, naturales de Corocorto, advertían a los españoles "como leales vasallos de S.M." sobre los movimientos de aucas y pehuenches que preparaban una posible invasión a Mendoza. ${ }^{22}$ Estos datos permiten considerar la plausibilidad histórica, sino la veracidad, de otro caso que ha sido considerado dudoso y que trataremos más adelante. El de la merced real de 1713 al cacique Diego Sayanca de la laguna de la Quijada ${ }^{23}$ que coincide con los aprestos bélicos en la frontera sudeste de Mendoza.

20 Espejo, 1954: 360-363.

21 Espejo, 1954: 546-547.

22 "Don Melchor Tunuyán y Don Diego Seme avisan a la ciudad de Mendoza sobre una reunión de indios", Morales Guiñazú, 1938: 208-209.

23 Existe una larga controversia sobre la autenticidad de este documento que he tratado en otro lugar, Escolar, 2020a. La principal impugnación a su contenido es que la fecha de la Merced, 1713, no coincide con el servicio activo de dichos funcionarios, 1723. Pero si tomamos en cuenta el contexto de producción del otro documento y las fuertes coincidencias en cuanto ¿Podría haberse otorgado una Merced de tierras en 1723 como parte de una apurada negociación de apoyo militar y un copista 
Entre 1660 y 1730 aumentó la beligerancia de los puelches, pehuenches y aucas en el sur mendocino que incursionaban en los Valle de Uco y Jaurúa al pie de la cordillera de los Andes "matando y destrozando" los españoles e indios sometidos en sus estancias al punto de provocar su abandono. ${ }^{24}$ A raíz de estos ataques, hacia fines del siglo XVII los españoles se habían replegado hacia el norte pero continuaron presionando sobre Uco y Jaurúa, una de las zonas ganaderas más importantes de la región por su proximidad con el Valle Central de Chile. Propiciaron entonces alianzas con parcialidades puelches que habitaban principalmente al sur del río Tunuyán, es decir, la zona fronteriza más inmediata a los enclaves españoles de Mendoza. Luego de un levantamiento de los puelches chiquillanes en 1680 al mando del cacique Lorenzo Chiquillán, parte de estos se alió con los españoles a cambio de tierras en el Valle de Jaurúa y aparentemente en Corocorto. En 1680 entonces "a raz̧ón de haber venido la nación chiquillan a dar la paz. cuando otras naciones estaban en guerra" se produjo la paz con los chiquillanes. ${ }^{25}$ En Cormañe, en el valle de Uco o el de Jaurua, ${ }^{26}$ se los redujo mandándoles abrir acequias para sus cultivos. ${ }^{27}$ Entre los caciques chiquillanes aliados se encontraban Don Melchor Tunuyán y Diego Seme o Semeyan, ${ }^{28}$ a los que aparentemente se agregaron otros como Sebastián Paucán que en 1704 es mencionado como cacique de una encomienda de Corocorto a la cual asistía "desde el alzamiento de Don Lorenzo Chiquillán". ${ }^{29}$

Las antiguas estancias del Valle de Uco y de Jaurúa se transformaron entonces en una "frontera de amortiguación" 30 y la frontera efectiva que había estado en el río Diamante, más al sur, quedó ubicada en el Tunuyán. Los chiquillanes y otros grupos que fueron pactando la paz ocuparon esas tierras como "indios amigos" cuya misión

posterior que escribió el texto que apareció a comienzos del siglo XIX transcribió mal un dígito de la fecha? En el texto de la merced preservado hasta el momento, y supuestamente falso, figuran las firmas de los mismos funcionarios que en 1723 tomaron declaración a los caciques de Corocorto, Diego Seme y Melchor Tunuyán, sobre la temida invasión de los aucas, el lugarteniente de Capitán General, Corregidor y Justicia Mayor Thomas de la Llana y el Teniente de Corregidor y Justicia Mayor don Ángelo Francisco de Mayorga.

24 Espejo, 1954: 237, Prieto, 2000.

25 Espejo, 1954: 513.

26 Espejo 1954: 676.

27 AHM, carp. 12, doc. 6. Según Prieto, Cormañe podría ser la ciénaga de Cormallín en el actual departamento de San Carlos.

28 Morales Guiñazú, 1938: 208-209.

29 Espejo, 1954: 546-547.

30 Prieto, 2000: 212. 
era guardar la frontera. Hacia 1701 se designó inclusive un corregidor a la reducción de los chiquillanes. ${ }^{31}$ Otros grupos provenientes del sur al parecer se fueron agregando a los primeros. Un informe del presidente de Chile sobre los puelches y pehuenches del lago Nahuel Huapi da cuenta de que para la época setenta familias de indios "pampas" se habían asentado en el Valle de Uco y que dos caciques habían ido a Mendoza insinuando al corregidor que si los dejaban asentarse recibirían gustosos un misionero. ${ }^{32}$ Los denominados pampas que recorrían las costas del Desaguadero al este también comenzaron a instalarse en el Valle de Uco y Jaurúa, que con el paulatino retorno de los españoles a las estancias se convirtió en un área multiétnica con fuertes tensiones y permanente amenaza de guerra. En este panorama, parece claro que los indígenas de diversas parcialidades negociaron durante algunas décadas con ventaja su relativo sometimiento, obteniendo acceso a la tierra a cambio de servicios militares, que a veces eran bastante vagos y se limitaban al hecho de no atacar a los españoles. A su vez, estas alianzas con los españoles o incluso algunas de las incursiones estaban dictadas tanto por la búsqueda de territorios de pastoreo como sobre todo por los conflictos con otras parcialidades que habitaban tanto al este como al oeste de la cordillera. Un cacique pampa, por ejemplo, afirmaba en 1724 haber venido con su gente a Jaurúa donde había estancias de españoles porque " $a$ su hermano lo querian matar otros indios de otra parcialidad de gente que llaman güiliche de arriba, auca [...] con el cacique del Río de los Sauces". 33

Continuaré el análisis sobre las tierras indígenas en Cuyo en relación con la dinámica de la frontera sur abordando los procesos de reconocimiento y litigios durante la segunda mitad del siglo XVIII, con un nuevo proceso fundacional encarado por a Junta de Poblaciones de Chile. Intentaré destacar la relación existente entre los reconocimientos a la posesión o propiedad de la tierra o su adjudicación y de cargos y liderazgos, en función de la geopolítica colonial, destacando las estrategias indígenas que aprovechaban las necesidades o debilidades militares de los españoles permitiendo sostener una agenda territorial a los huarpes y puelches reducidos. Mostraré además como junto al caso de Corocorto, la situación de eventual

31 AHM, carp. 12, doc. 2.

32 Archivo General de Indias (en Adelante AGI), Chile, leg. $\mathrm{n}^{\circ} 159$.

33 AHM, carp. 29, doc. 15. 
reconocimiento territorial de los indígenas del centro de Cuyo, en particular en las Lagunas de Guanacache, continuó relacionada con esta dinámica hasta fines del período colonial. En el último cuarto del siglo, luego de que Cuyo es incorporado al Virreinato del Río de la Plata en 1776, la reanudación de los proyectos fundacionales en ambas áreas tuvo como principal objetivo ocupar con poblaciones ya incorporadas el espacio de frontera en retroceso frente a los pampas y ranqueles al sureste de los ríos Desaguadero y Tunuyán.

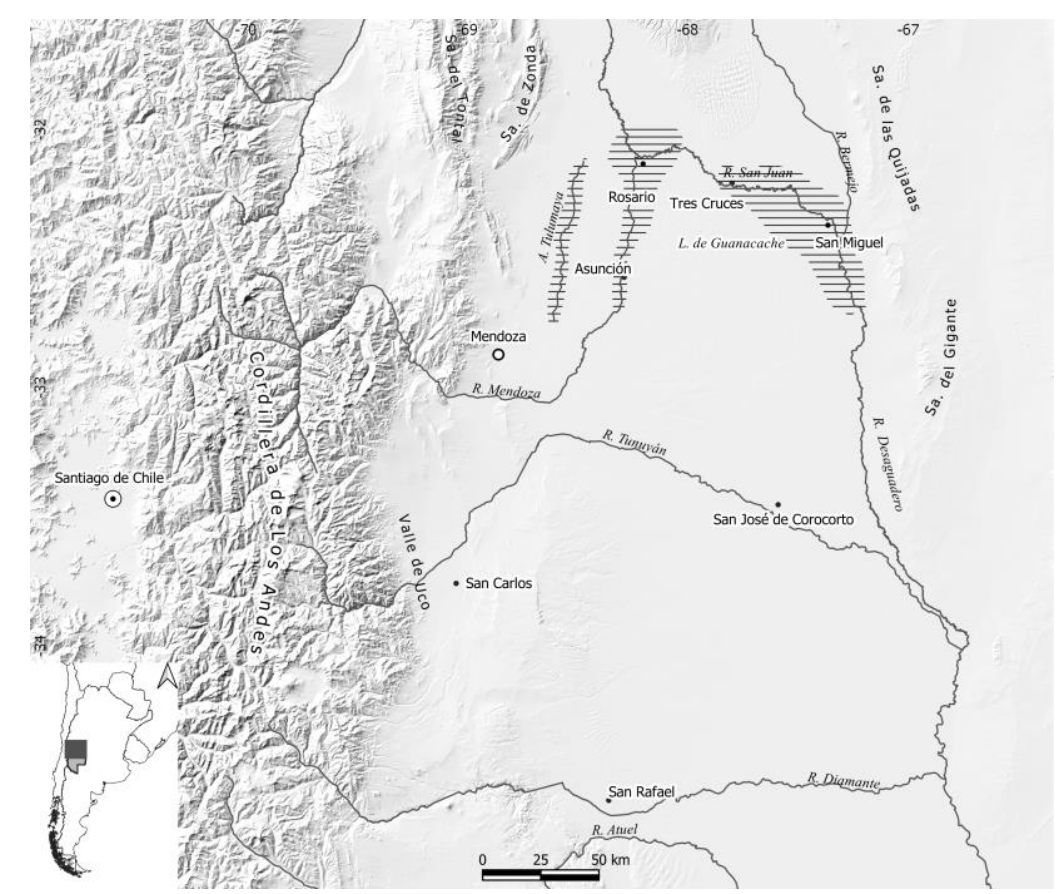

Mapa 1: Centro y Sur de Cuyo en el siglo XVIII. Situación de Corocorto y los pueblos de indios de las Lagunas de Guanacache. Realización: Laura Zalazar.

\section{Fundaciones de pueblos de indios y conflictos con los españoles}

Entre los caciques chiquillanes a los cuales se les adjudicaron o reconocieron tierras en Corocorto a raíz de su pacto con los españoles en la reducción de Lorenzo Chiquillán se encontraba, como he mencionado anteriormente, Diego Seme o Semeyan. Hasta el momento no ha sido destacada la continuidad de este linaje y la 
defensa de sus tierras hasta principios del siglo XIX, siguiendo una característica también observada en Mogna con los caciques Alcani. ${ }^{34}$

Avanzado el siglo XVIII la zona de Corocorto comenzó a ser cada vez más atractiva para terratenientes y comerciantes de Mendoza por el aumento del transporte carretero con Buenos Aires y Córdoba, cuya ruta pasaba por las inmediaciones. Las pasturas eran procuradas para abastecer mulas y caballos y criar ganado y la madera de algarrobo era buscada para rodrigones de viñedos, construcción de carros y viviendas y leña. ${ }^{35} \mathrm{La}$ competencia por el territorio generó un nuevo ciclo de conflictos. En 1743, hacia la desembocadura del Río Tunuyán, el Maestre de Campo Don Francisco Mayorga pidió desalojar al cacique Diego Lemu "el zurdo," quien considero muy probablemente sea el mencionado Diego Seme o Semeyán, con su familia y agregados. ${ }^{36}$ Mayorga argumentaba poseer la escritura de 2500 cuadras de tierra vendidas a su padre en 1703, de parte unos títulos de merced de 1629. Se dio intervención al protector de indios quien impugnó el reclamo aduciendo que la causa estaba radicada en la Real Audiencia, por lo cual el juicio "sobre la propiedad y señorio a dichas tierras" debía ser continuado en aquel tribunal

...esa causa está radicada ante los señores de la Real Audiencia por haberse presentado ante dichos señores Nicolás Moyano indio con poder del Cacique Don Diego el zurdo que llaman por cuyo motivo ordenaron y mandaron por despacho dichos señores al general Don Juan Bermionsola que era corregidor al presente hiciese una sumaria información para saber el paraje donde son las tierras mencionadas que demanda dicho Maestre de Campo Don Angelo Francisco de Mayorga y que fecha dicha información luego la remitiese como así lo bizo dicho general Don Juan de Bermionsola por lo cual se ha de servir [...] mandar a dicho Maestre de Campo ocurra ante dichos señores de la Real Audiencia

Hacia 1751 los indios de Corocorto reclamaron y obtuvieron el derecho al cobro de una tasa por la explotación de la madera, situación que originó conflictos con comerciantes por los recursos del lugar. Al parecer ya existía o se fundó en la ocasión un pueblo de indios, al menos en los papeles, según evidencia la confusión al respecto. El mismo año, ante la negativa de pago por parte de un comerciante

34 Escolar, 2020b.

35 Prieto \& Abraham, 2000.

36 AHM, carp. 164, doc. 38. 
portugués, el alcalde Marcelo Díaz amenazó al superintendente del partido con que los indios se retirarían del pueblo. Este reclamo sirvió para que el superintendente adujera que en la zona no existían pueblos formados ni curas doctrineros, como se había informado un mes atrás en otro dictamen. ${ }^{37}$ Los conflictos fueron escalando e involucraron al cacique y al alcalde. En 1755 el protector de Mendoza radicó una denuncia del cacique Joseph Semeyan sobre introducción de ganado y extracción de madera en sus tierras sin pagar arriendo. ${ }^{38}$ Acusó al alcalde Marcelo, quien desde hacía siete años ostentaba el cargo, que no era natural de allí y usurpaba las tierras y el agua para él y sus acólitos. ${ }^{39}$ También decía que arrendaba las tierras a españoles recibiendo él solo el estipendio a pesar de que los "legítimos dueños" eran Joseph Semeyan y sus deudos, mientras que el alcalde solo tenía la parcela de tierra "que les señaló el año pasado el señor Don Gregorio Blanco de Laisequilla, Oidor de la Real Audiencia de este reino, para que viviere por no ser natural de Corocorto".

En el mismo pleito, al igual que en el caso de Mogna y Valle Fértil que no analizarmos aquí, se disputó la posesión de documentos. Una de las principales demandas de Semeyan fue que Don Francisco de Videla, vecino de Mendoza, le restituyera "un papel o instrumento para sacar una copia el que no se le ha devuelto" y que le había entregado su padre, Diego Semeyan. Estos documentos son necesariamente anteriores a los de la fundación que se intentaría concretar al año siguiente, y podrían estar relacionados con otro acto más antiguo de otorgamiento de tierras o el cacicazgo. Además, como mostramos antes, remonta los archivos de los caciques o comunidades por lo menos hasta principios del siglo XVIII. El fiscal ordenó finalmente que el escribano Don Francisco de Videla, bajo apremio, restituyera a Joseph Semeyan el "instrumento" y que "se dividan a los indios tierras, aguas y montes".

En 1756 se fundó el pueblo de Corocorto ${ }^{40}$ y fueron repartidos solares a los indios según su jerarquía, como era de uso. Don Joseph Semeyán mencionaba las herramientas que se les entregaron "para el común beneficio de los indios y que labrasen sus tierras" por ser dueños de "aguas, tierras y montes" al mismo tiempo que renovaba sus

37 ANC, Real Audiencia, vol. 2907, f. 76-77.

38 AHM, carp. 29, doc. 22.

$39 \mathrm{El}$ acalde llevaba siete años en el cargo pero la fundación del pueblo por el oidor Blanco había sido el año anterior, según manifiesta el Protector en el mismo documento. Por lo que se comprueba que existían autoridades coloniales nombradas y un pueblo previamente a ese ciclo fundacional.

40 AGI, Chile, leg. nº 138. 
quejas por la introducción de foráneos en sus tierras. ${ }^{41}$ Pocos años después - como ocurrió con todas las demás fundaciones o intentos de fundación de pueblos en Valle Fértil, Mogna y las Lagunas - Corocorto se hallaba nuevamente despoblada, al decir de un informe de la época, debido a los continuos ataques de los "indios enemigos." Sus habitantes se habían retirado al noroeste, a las lagunas de Guanacache, precisamente a los parajes de Capilla del Rosario, Asunción y San Miguel.

Hacia 1789 se produjo una renovada presión de las autoridades del virreinato del Río de la Plata por reforzar las fronteras contra los indígenas libres y las vías de comunicación internas del dominio colonial. El famoso comandante de armas de Mendoza José Francisco de Amigorena, quien para la misma época desarrolló una política de alianzas selectivas con grupos pehuenches que garantizaran la frontera sur fue encomendado por el Virrey Marqués de Loreto para inspeccionar el área de Guanacache y para repoblar Corocorto, punto estratégico en la frontera, como veremos más adelante. Admitiendo sostener al poblado de Capilla del Rosario en su ubicación, conminó empero a los habitantes de Asunción y San Miguel a repoblarse en Corocorto y les ofreció para ello guarnición armada y acequia de regadío. ${ }^{42}$ Amigorena logró que vecinos de la ciudad de Mendoza que poseían propiedades en Corocorto donasen 2.000 cuadras de tierras para fundar una Villa, y en diciembre de 1791 Amigorena pasó revista a las milicias del lugar y las dotó de armas y municiones, además de agregar soldados hasta sumar 41 hombres. Hizo abrir una acequia y logró reunir 45 familias a las que exhortó a poblarse por "el beneficio que les redundaria la sociedad en forma de república".

Aunque el comandante de armas nunca mencionó el pueblo de indios en Corocorto ni la existencia de sus autoridades, la villa fue poblada, al igual que las otras del ciclo de fundaciones iniciado por la Junta de Poblaciones de Chile (Valle Fértil y Jáchal), y los pueblos (Mogna y las Lagunas), básicamente por indios. El cura Obredor, a cargo de todos los parajes mencionados informó que sus feligreses eran en su mayoría "indios puros", "descendientes de los primeros pobladores infieles" y que su principal ocupación era la crianza de ganado de invernada. ${ }^{43} 144$ de ellos estaban matriculados en 
Corocorto, 243 en Rosario y 180 en Asunción y San Miguel; pero la mayoría vivían sin paradero determinado en ranchos dispersos en el monte por miedo a las invasiones y otros en estancias que se encontraban a 15 leguas.

Inclusive, estos tenían el reconocimiento de sus tierras pese a que no existía un pueblo de indios propiamente dicho, excepto la fundación de 1756. Entre 1804 y 1807 el cura de Corocorto Juan Crisóstomo Pérez se opuso como defensor de los indios a una denuncia de tierras hecha por Don Mateo Delgado en el paraje de La Paz, a ambos lados del río Desaguadero. ${ }^{44}$ La denuncia o denuncio de terrenos y el posterior remate era el procedimiento legal desde la Real Instrucción de Independientes de 1754 para la apropiación privada de tierras consideradas realengas, es decir sin propietario. ${ }^{45}$ En este caso, Rafael de Sobremonte entonces virrey del virreinato del Río de la Plata suscribía al propio Pérez el oficio en que se ordenaba realizar la mensura en base al denuncio. Delgado era un empresario de tropas de mulas y carretas que disputaba el control del camino a Buenos Aires y las tierras de pastoreo en el área, junto con el derecho a cruzar el río Desaguadero por un puente que a fines del siglo XVIII fue objeto de una gran controversia legal. ${ }^{46}$ Pérez escribió a Sobremonte cuestionando por "quererles robar a cara descubierta a estos infelices lo que legitimamente es suyo".

¿...Cómo puede el virrey anular una donación Real hecha en nombre de su magestad, con particular comisión por el Sr, Oidor Blanco como es constante? Cómo puede el dicho Virrey desposeer una posesión jurídica que les dio este Ministro Real estando, como están en actual, inmemorial, y no interrumpida posesión de dichos terrenos sus legitimos dueños?

El defensor acudió así a dos argumentos distintos que probaban la posesión por parte de los indios: la prescripción por posesión inmemorial y la donación implicada en la reducción del pueblo fundado en $1756 .{ }^{47}$ Pérez denunció una intención fraudulenta de despojar a los indios en la que podría verse involucrado el propio Virrey: "si los terrenos son realengos (como dice el denunciante y usted supone) $\dot{i} A$ qué fin se me hace saber esta providencia? Luego, conocen que los indios poseedores son legítimos dueños". En esa

44 AHM, carp. 30, I, doc. 50.

45 Cueto, 1989.

46 Sosa Morales, 1965: 56-63.

47 Cueto, 1989. 
línea cuestionó el hecho de que el protector de indios de la ciudad, que debía haber tomado la defensa, no había intervenido, sea porque Sobremonte eludió darle vista del expediente o porque el propio defensor se había negado. Pérez, aceptando esta última posibilidad (que exculpaba al Virrey), dijo que se había constituido como defensor sólo "en defecto de aquel" agregando que le hiciera saber "que siempre que este haga constar, que no quiere hacer, yo me apersonaré y bajaré a hacer su defensa, y el castigo y deposición de aquél, si no lo hace". Finalmente, denunció también maniobras de ocultamiento de los títulos originales de la propiedad de los indios por parte de los funcionarios del cabildo de Mendoza

...pues sacando del Archivo de ese cabildo los documentos originales de la donación y posesión Real que se les dio a los indios de estos terrenos, desde el Agua Dulce, que es el fondo del Rincón que forma el Tunuyan hasta el mismo Corocorto, no habría más que hacer. Pero no lo he podido conseguir sin embargo de tantas representaciones que ahora reitero [...] Pues aun cuando diga ese cabildo, que no existen dichos. documentos (como se dice) es lo más fácil saber en tiempo de qué escribano se han substraído con (i?) los mismos inventarios de las anteriores entregas del protocolo

Más allá de su encarnizada defensa legal, los juicios sobre la población indígena por parte de Pérez son contradictorios. En diversas oportunidades se queja amargamente de la indolencia y falta de respeto de los indios. Esto se vincula a las dificultades que encuentra para un megalómano proyecto de desarrollo para el área que insistentemente despliega en sus cartas a Sobremonte. En junio de 1807 escribe al cabildo de San Luis que a pesar de que habían transcurrido sesenta años desde la fundación del pueblo, los naturales tenían aversión a la agricultura y a todo trabajo y que se andaban "mudando de un lugar a otro y viven en chozas miserables peor que los animales". ${ }^{48}$ El mismo mes dirigió otra carta al Virrey diciendo que la Villa de Corocorto estaba destruida y que lo habían dejado solo "en este desierto". Que era hostigado por parte del Comisionado del gobierno de Mendoza, quien había convocado a los indios situados en la villa que "se vinieron a insultarme a la misma iglesia, amenazándome que me habian de amansar?. ${ }^{49}$

En la misma carta volvió a denunciar a Mateo Delgado por querer apropiarse de

48 Archivo General de la Nación (en adelante AGN), Sala IX- 3-5-2, f. 3.

49 Ibid. f. 7-8. 
...el mejor territorio que tiene el lugar por realengo y baldio, teniendo más de 200 almas y siendo legitimamente de mis feligreses [...] sin embargo de las reiteradas representaciones a la Real Audiencia, virrey, Gobernador de Córdoba y Subdelegado [...] estando en actual, quieta y pacifica posesión sus legitimos dueños ${ }^{50}$

Finalmente, nos enteramos de que el último cacique de Corocorto había sido Pedro Semeyán y que este había fallecido el mismo año porque se menciona a su viuda como objeto de la violencia de Delgado, el cual parece haber aprovechado para matarla y ocupar sus tierras.

...llegando a tanto la iniquidad que el mismo capataz de Delgado bubo de matar a espolazos a la viuda del cacique Pedro Semellan, haberle pegado fuego a su corral, e irla a buscar con otros armados para matarla, y se ha quedado impune pues aunque a mi instancia, promovió la Real Audiencia el asunto, en Mendoza lo ban suprimido

Pérez amplió su cuestionamiento a las autoridades de Mendoza mostrando su corrupción generalizada: "nombran alcalde, corregidor y procurador de su parcialidad para no tener ninguna oposición" y con un singular verso cierra una denuncia por el cobro de tasas ilegales a nombre del rey a los troperos del camino Real: "Esta contribución se distribuye como la limosna de nuestra señora de las Estrellas, esto es, la mitad para mí, y la otra, para ella". Finalmente Sobremonte atendió el reclamo del defensor y ordenó la suspensión de las mensuras, aceptando los derechos de los indios y oponiéndose a las pretensiones del cabildo mendocino. ${ }^{51}$

\section{Las lagunas de Guanacache y el Desaguadero como frente colonial}

Desde el siglo XVI se otorgaron en las lagunas de Guanacache la mayor cantidad de encomiendas de indios huarpes en la región y fue también una de las principales áreas de saca de indios. Las encomiendas, al igual que las sacas, se utilizaron en su gran mayoría como base para la extracción de mano de obra indígena hacia Chile y no se

50 Ibid. f. 9.

51 Ibid. f. 19. 
crearon asentamientos permanentes. En 1664 el Oidor Cuba y Arce fundó el primer pueblo de que tengamos datos, en el sitio que llamaban del Corral, o el Corral de Chaparro, junto a las lagunas a doce leguas de esta ciudad, donde edificó ranchos y construyó una iglesia poniendo a dos caciques como alcaldes y un administrador español. ${ }^{52}$ Uno de esos caciques reducidos con "todos los indios de las Lagunas" era Bartolomé Talquinca. Como vimos, unos años más tarde en 1696 se afirmaba que su descendiente Juan Talquinca había servido "como tales caciques" "en las entradas del enemigo", contra los chiquillanes, hasta el río Atuel. ${ }^{53}$

A mediados del siglo XVIII, como hemos visto, la Junta de Poblaciones de Chile determinó que se establecieran pueblos de indios en las Lagunas. En 1753 ordenó al corregidor de Cuyo, Eusebio de Lima y Melo, que repartiera tierras a los indios y construya iglesia y casa para el cura, no sin antes intentar persuadirlos de poblar en Corocorto, con el argumento de que el pueblo de indios existente en las Lagunas se hallaba en una tierra estéril y medanosa y que en cambio en Corocorto era fértil y abundaba el agua y la madera. A mediados del mismo año Lima y Melo hizo citar a los pobladores de los parajes de San Miguel y Asunción - ambos distritos ubicados actualmente en Mendoza - y realizó una matrícula de los mismos, cuyo padrones muestran en el área la mayor cantidad de población de todos los pueblos erigidos a instancias de la Junta de Poblaciones en Cuyo, con 81 grupos familiares con un total de 488 personas, 50 en San Miguel (288) y 31 en Asunción (199). ${ }^{54}$ Pero el reparto de solares y la formación del pueblo con sus cuadras, plaza e iglesia se suspendió por no haber concurrido todos los indios que constaban en la matrícula. El optimismo reduccional se revelaría excesivo. Al igual que en los casos que hemos visto hubo marchas y contramarchas sobre la localización del pueblo por la resistencia opuesta por los indígenas, la cual no fue una respuesta monolítica sino que derivó también de antagonismos preexistentes entre ellos. En San Miguel, donde se había realizado la primera compulsa, los pobladores sugirieron enfáticamente el emplazamiento en Tres Cruces, tres leguas al oeste, ${ }^{55}$ donde según afirmaron se podía sacar agua del río (al contrario que en San Miguel donde el río corría encajonado muy abajo). El

52 AGI, Escribanía 939 A; Prieto, 2000: 170.

53 Espejo, 1954: 360-363.

54 ANC, Real Audiencia, vol. 2907, f. 141.

55 Se halla a menos de $15 \mathrm{~km}$ del actual pueblo de San Miguel, frente al paraje del Encón. 
corregidor realizó una inspección comprobando supuestamente la factibilidad de realizar una toma y acequia para regar tierras, ya que la barranca del río era menos pronunciada que en el resto de la costa. La Junta de Poblaciones aprobó la ubicación y mandó se fundase el pueblo y repartieran los solares de tierras e instruyó para ello al oidor Blanco de Laysequilla, quien citó a los pobladores de San Miguel y Asunción en Tres Cruces para fundar "el pueblo de las Lagunas". ${ }^{56} \mathrm{El} 23$ de julio de 1754 Blanco acudió a realizarlo y aunque comprobó que pese a lo manifestado por los pobladores y Lima y Melo la profundidad del cajón del río no permitiría sacar agua, los pobladores insistieron en concretar el reparto lo cual se realizó de inmediato.

Los habitantes de Asunción, no obstante, resistieron habitar allí por los mismos motivos que observó Blanco, a lo que agregaron la escasez de tierras aptas para cultivo. ${ }^{57}$ El mismo día el oidor aceptó su contrapropuesta de fundar el pueblo en Asunción, para lo cual encargó revisar el terreno al superintendente de las Lagunas, Matías Barros, y a los ancianos del lugar. Esta pesquisa arrojó que en las inmediaciones de la capilla ya existente había suficiente tierra plana apta para sembrar y con facilidades de riego. Los pobladores dijeron que aceptaban construir el pueblo si les deban herramientas y sobre todo si se les aseguraba que no serían desalojados por nadie en lo sucesivo. La nueva fundación fue aprobada, Barros entregó las herramientas al alcalde Pascual González ${ }^{58}$ y Blanco ordenó trasladar a todos los habitantes de San Miguel a Asunción, donde quedarían divididos de los de allí y con su propio alcalde, mientras que su ganado podía continuar en San Miguel. ${ }^{59}$ Barros renunció en diciembre del mismo año alegando tener que trabajar para mantener su numerosa familia y los de San Miguel, como era de esperar, no se trasladaron a Asunción bajo la excusa de que el terreno se inundaba habitualmente por las crecidas del río. Finalmente, quedaron vigentes ambos pueblos con sus propios alcaldes electos. ${ }^{60}$ Pero los conflictos por las tierras y la autoridad continuaron a lo largo del siglo. En 1771 el alcalde de Asunción Feliciano Díaz solicitó la actuación del protector de naturales contra María Chuquia que reclamaba unas tierras como

56 ANC, Real Audiencia vol. 2907, f. 141.

57 Ibid. f. 147. El terreno se encontraba entre dos cadenas de médanos y poseía escasa superficie plana.

58 Ibid. f. 147, 150.

59 Ibid. f. 153.

60 ANC, Morla Vicuña, vol. 22, f. 76-77. 
herencia pero éste termina representando a Chuquía, ${ }^{61}$ alegando su posesión inmemorial ante la desaparición de unos documentos que "se perdieron en una avenida grande que bubo, cuya notoriedad me releva de prueba". ${ }^{62}$ Luego, se evidencia la confrontación política por los cargos de alcaldes, que terminó derivando en su unificación para los dos pueblos. En 1772 el protector de naturales reclamó que a Miguel de Covarrubias le había sido quitado el cargo de alcalde de Asunción y San Miguel. Y aunque San Miguel tenía el suyo, Covarrubias fue confirmado como alcalde de ambos pueblos. ${ }^{63}$



Mapa 2: Las Lagunas de Guanacache en el siglo XVIII Realización: Laura Zalazar.

Más allá de estos pormenores, los laguneros como los habitantes de otros parajes de reducción parecen haber continuado ocupando sus tierras con reconocimiento por parte del gobierno colonial. Prueba de ello es que en 1785 Sobremonte admitió que no podía dar lugar a los reclamos de vecinos de la ciudad de San Juan para apropiarse de las tierras de las Lagunas de Guanacache y en Mogna porque los indígenas tenían real provisión de la audiencia de Chile sobre las mismas. ${ }^{64}$ Lo mismo que en el caso

61 AHM, carp. 140, docs. 20 y 24.

62 AHM, carp. 140, doc. 24.

63 Espejo, 1954: 689-700.

64 Torre Revello, 1946: XCVI, XCVII. 
de Corocorto, según recordaría dos años después al propio Sobremonte el defensor de los indios. ${ }^{65}$

En su informe escribió que en Mogna y las Lagunas tenían real provisión de la Audiencia de Chile para el uso de sus tierras y además no pagaban tributo, dato que reiterará en $1796 .{ }^{66}$

...por aquellas dilatadas llanuras y quebradas que de tiempo inmemorial viven de esta forma sin que los jueces sean bastantes a vigilar sus operaciones, ni pueda alcanzarles el Pasto Espiritual, y es presumiblemente que al quererlas sacar de este género de vida para reunirlos a población se profugan los más porque aborrecen la sociedad, y los del paraje que llaman Mogna y las lagunas, tienen real provisión de la audiencia de Chile para que se les deje el uso de la tierra [...] por su constitución no pagan tributo, no merecen las tierras que poseen y solo viven ociosa e inútilmente en sus ranchos infelices, robando el ganado de las estancias inmediatas ${ }^{67}$

Desde el siglo XVII la significación estratégica para la geopolítica colonial de los indígenas de las Lagunas y Corocorto con relación al territorio de dominio de pampas, aucas y pehuenches que se extendía hacia el este y sureste desde los ríos Desaguadero y Tunuyán parece haber funcionado como fundamento para la posesión y propiedad de sus tierras. Dicha posición era reforzada por la dificultad de poblar con españoles el área debido a su complicada geografía. Para fines del siglo XVIII, en plena restauración borbónica y recién fundado el virreinato del Río de la Plata, la región capturó en forma renovada la atención estatal ante los intentos de fortalecer la frontera con los indígenas no sometidos y retomar el control de áreas que estaban siendo parcialmente reocupadas u hostigadas por estos. Como hemos visto, el comandante de armas de Mendoza José Francisco de Amigorena, artífice de una política exitosa de reforzamiento de la frontera sur de Cuyo, fue comisionado para desarrollar un proyecto de fortalecimiento fronterizo para lo cual entre otras cosas repobló y refundó el pueblo de Corocorto. Pero como parte de la misma misión debió relevar el área de las Lagunas, produciendo un informe y un diario de

65 AHM, carp. 27, doc. 50.

66 Garzón, 1968: 471.

67 Torre Revelo, 1946: XCVI. 
viaje que son tal vez las fuentes más importantes sobre el área y sus pobladores para el período. ${ }^{68}$

Este renovado interés del gobierno colonial se debió principalmente al objetivo de salvaguardar las rutas de comercio frente a la amenaza que suponían las incursiones de los indígenas libres de su dominio, pero también de dotar de agua a la travesía para los animales de transporte y las personas. El camino de Mendoza a Buenos Aires, por donde circulaba un importante comercio carretero que a su vez conectaba con Chile y el Alto Perú, pasaba por el sur del área de Guanacache y cruzaba el río Desaguadero, que en el verano no tenía agua a partir de la laguna de Las Quijadas. El principal objetivo del relevamiento de Amigorena eran dotar de agua potable a la travesía para abastecer los viajeros y las tropas de mulas y carretas, y reforzar la frontera para evitar la introducción de los indígenas alzados. Todas estas preocupaciones se relacionaban de forma directa con la hidro-geografía de las lagunas de Guanacache. El proyecto para el aprovisionamiento de agua era ambicioso: conseguir un caudal permanente en el Desaguadero y realizar aguadas o represas ("aljibes") que pudieran llenarse en invierno y mantenerse en verano. Pero la idea de mantener con agua el río aparejaba un grave riesgo: que ante la perspectiva de obtenerla para sus incursiones en la árida región, los indígenas alzados amenazaran el tráfico carretero y corrieran de hecho la frontera hacia el norte. Por ello, era fundamental también la fijación de poblaciones leales en el Desaguadero que pudieran limitar esa afluencia. Este era el papel reservado, como ocurría desde el siglo XVII, a los indígenas incorporados de las Lagunas y Corocorto.

Demostrando la importancia que adquirió el área, Amigorena realizó una minuciosa inspección en todo el arco de lagunas desde el paraje de Capilla del Rosario hasta Corocorto. Con la participación del ingeniero José Jiménez Inguanzo hizo levantar un impresionante mapa que hasta la actualidad es el más detallado jamás realizado sobre el área sin medios satelitales. ${ }^{69}$ Todos los puntos poblados, relieve, vegetación, caminos (incluyendo sobre todo los "caminos de los indios" y los "ranchos de los indios") fueron cartografiados y las lagunas sondeadas en toda su extensión. Estas llegaban

68 Esto consideraba el antropólogo Milcíades Alejo Vignati (1953), quien publicó ambos documentos considerándolos como las principales fuentes etnohistóricas sobre los huarpes o sus descendientes en las Lagunas para la época. El mismo diario es citado posteriormente por Sosa Morales (1965: 56-63) 69 Vignati, 1953. 
hasta los 18 pies de hondo y aunque eran consideradas como diversas, unidas por canales o separadas, formaban en las grandes crecidas una sola jalonada por inmensos totorales que crecían donde había menor profundidad. Para la época comenzaban a perder sus caudales, retrogradándose hasta secarse a veces las de más al sur, a lo largo del Desaguadero, como las de Las Quijadas, La Faltriquera y Los Chomes.

Si el informe de Amigorena, que retomaremos en breve, nos introduce en las viscisitudes hidrográficas y geopolíticas del área, su diario de viaje es el primer documento que reseña extensamente y de primera mano las costumbres y situación de los laguneros, además de la relación del estado colonial (en este caso representado por su persona) con los que aparecen como sus antagonistas principales: los propios laguneros y la naturaleza. El acceso a los parajes habitados de las lagunas no era tarea fácil aún para un experimentado militar de frontera con la disponibilidad de medios que podemos imaginar por su cargo y comisión virreinal. Estos totorales eran según describiría Bialett Massé un siglo después, "más altos que los de la manigua cubana" "70 y junto con los esteros, pantanos, bosques y arenales que los circundaban formaban una geografía defensiva que los laguneros habían aprovechado desde los inicios de la conquista. El calor era agobiante aún en época invernal. El 2 de agosto Amigorena tuvo que acampar a las nueve de la mañana por "la fuerza del sol” y luego continuar toda la tarde y noche hasta el siguiente destino. ${ }^{71}$ Pero lo peor de esa naturaleza hostil era, notablemente, la población de mosquitos, jejenes y zancudos que hacían insoportable la existencia. ${ }^{72}$ Amigorena repite en diversas oportunidades su padecimiento. "Las ricas truchas que producen estas lagunas bicieron algo tolerable la insufrible fatiga con que nos mortifican los innumerables insectos de mosquitos y jejenes". ${ }^{73}$ Más adelante describe una jornada en que los mosquitos "bicieron la guerra todo el día, pero [...] cuando entró la noche, vinieron ejércitos de otros que llaman zancudos, que a pesar de los bumazos de estiércol de vaca que pusimos en los toldos no podíamos librarnos". Y luego abunda: "al ponerse

70 Bialett Massé, 1985: 415.

71 Vignati, 1953: 82. Las descripciones de Amigorena coinciden con mis propias experiencias en la zona. Desde fines de la primavera es muy difícil estar al aire libre después de las nueve o diez de la mañana porque el calentamiento de la arena genera una atmósfera calcinante. Durante una temporada una medición de temperatura que realicé en Lagunas del Rosario arrojó 52 grados centígrados a las 12 am.

72 Vignati, 1953: 77.

73 Vignati, 1953: 75. 
el sol notamos que salian de los carrizales varios humos [...] y vimos que eran innumerables ejércitos de mosquitos zancudos". ${ }^{74}$ Parece exagerado que un hombre curtido en la guerra contra los pehuenches en la frontera sur de Mendoza insistiera con tales metáforas bélicas para ilustrar la acción de los insectos. Sin embargo, estas mismas imágenes fueron utilizadas por cronistas y misioneros en siglos anteriores para expresar los hechos.

El diario del viaje abunda en pareceres personales sobre las condiciones ambientales, los objetivos y dificultades de los proyectos a realizar y también sobre los propios laguneros. Estos son acusados de indolentes, indisciplinados y sin ambición económica. "Por alli habitan unos altaneros y vagos que viven ociosos y abandonados" que "se contentan con adquirir lo muy preciso para no morir de necesidad y que no se les vean las carnes". ${ }^{75}$ Le resultaba notable "la miseria que padecen estos naturales por la inacción y la flojedad, en medio de las buenas proporciones para repararse" y que "a manera de brutos se han determinado a vivir dispersos en los campos". ${ }^{76}$ Existían en efecto "buenas proporciones para repararse", es decir recursos relativamente abundantes y diversas actividades productivas. Principalmente la pesca, que aunque en la época no era objeto de un gran despliegue comercial, había abastecido a las ciudades de Cuyo e incluso a Santiago de Chile con pescados frescos o secados al sol. ${ }^{77}$ Otro renglón significativo era la recolección de sal y la tejeduría, actividad principal de las mujeres con la que según Amigorena "sostienen las familias y a los mismos hombres". ${ }^{78}$

Pero seguramente, tal como mencionaron otros observadores de la época, como el cura de la región de Corocorto y las Lagunas Juan Manuel Obredor, la ganadería era la principal actividad de los laguneros, especialmente de ganado de invernada. ${ }^{79}$ Los

74 Vignati, 1953: 77.

75 Sosa Morales, 1965: 56-68.

76 Vignati, 1953: 76.

77 Esta se realizaba mediante la utilización de grandes redes, movidas e inspeccionadas con balsas de juncos de origen precolombino, cuyo su uso está abundantemente documentado desde principios del período colonial hasta la década de 1940. La actividad, en general patrimonio de los laguneros, fue objeto a lo largo del tiempo de disputas por su explotación comercial y la utilización de mano de obra indígena. En 1623 por ejemplo una defensa "del cacique e indios del Pueblo de Guanacache y sus lagunas en la provincia de Cuyo" planteaba que el corregidor provincial había nombrado un amigo como corregidor del pueblo y Lagunas de Guanacache que ocupaba "a los miserables indios en las pesquerías" "y los despacha con recuas de mulas y ganados a las ciudades de Córdoba y La Rioja con la pesca sacada" prohibiéndoles que siembren para sustentarse, Espejo, 1954, T. 1: 69-70.

78 Vignati, 1953: 81-82.

79 Sosa Morales, 1965: 65. 
laguneros criaban cabras, ovejas, vacas, caballos y sobre todo mulas, cuya calidad continuó siendo afamada en toda la región inclusive, como nota Vignati con sorpresa, hasta la época en que escribe su artículo. ${ }^{80}$ Las Lagunas eran un centro importante de un circuito de crianza y tráfico de ganado en pie con destino a Chile, que se nutría con animales traficados desde la llanura pampeana y Córdoba y engordados en invierno en las áreas llanas en torno a los humedales de Cuyo, para luego ser trasladado en el verano a través de la cordillera. ${ }^{81}$ Además de todas estas prácticas económicas, la mayor parte de la dieta se obtenía de la pesca, la caza de aves, quirquinchos y guanacos y la recolección de huevos y vegetales, sobre todo de vainas de algarrobo.

Llama la atención sin embargo la nula mención de Amigorena a la agricultura, pese a que su propuesta de ofrecer en Corocorto tierras para cultivo a los laguneros, más los antecedentes de similares preocupaciones durante las fundaciones de pueblos de años anteriores, sugiere que éstos tenían práctica e interés en la misma. Es posible que tal actividad no haya sido significativa en el período, o incluso que no existiera, como han planteado algunos autores. Sin embargo, también es probable que los laguneros hayan ocultado sus sitios de cultivo o que el propio Amigorena, interesado en justificar las obras hídricas para la fundación de Corocorto como emporio agrícola, haya obviado mencionar su práctica en otros parajes de la cuenca palustre sobre los que no podía disponer la concesión de tierras a foráneos. Algo similar puede haber ocurrido con la nula consideración del Maestre de Campo a la ganadería, que al igual que la agricultura denotaría un uso de la tierra que para la época era un argumento de legitimación de la posesión de la misma, con valor por ejemplo en litigios judiciales. El informe realizado por Amigorena, al contrario que el diario, estaba centrado principalmente en el régimen hídrico del complejo palustre. Consistió en una encuesta a los "prácticos del lugar", en general autoridades locales, sobre las siguientes preguntas: reconocer la situación hidrográfica de las Lagunas para cotejar si con ciertas obras, básicamente cortes en los endicamientos naturales (denominados localmente "bordos") entre lagunas, se podría dotar de agua permanente al río Desaguadero, pero evitando que se vacíen las lagunas y perjudique la pesca; evaluar si 
los "indios bárbaros" podían internarse para obtener agua o por el contrario, podía lograrse por este medio que se poblaran con agricultores criollos esos parajes; y finalmente, qué medio era más seguro para abastecer de agua, si el del cauce permanente o la realización de aljibes. La hidrografía era sin duda la principal preocupación, por la cambiante dinámica de los cauces no sólo de las lagunas sino de los ríos. El río Mendoza, principal formador de la cuenca, variaba su curso según la dirección de las crecientes cuando inundaba repentinamente la llanura, o cuando el movimiento de los médanos taponaba parcialmente su cauce cuando se secaba. Precisamente doce años antes el río había cambiado de curso corriéndose decenas de kilómetros hacia el norte, desde San Miguel hacia la capilla del Rosario. ${ }^{82}$

Los prácticos consultados fueron, excepto un par de casos, las principales autoridades locales reconocidas por el funcionario en su periplo a lo largo de todo el arco de lagunas: Los alcaldes y mandos militares que allí revistaban. ${ }^{83}$ Las respuestas dieron referencias sobre las inquietudes del relevamiento, pero -sobre todo las más completas - también intentaron influir sobre el proyecto desde sus intereses. Los que habitaban en Lagunas del Rosario se excusaron de opinar sobre el posible éxito de las obras, excepto el Alcalde Pedáneo Feliciano Díaz, quien ofreció un extenso reporte describiendo la hidrografía y cuestionando la posibilidad de proveer en forma permanente al Desaguadero.

...dichas Lagunas [...] corren desde el camino de San Juan de poniente la naciente, hasta donde desembocan en un río caudaloso, que este declarante, y otros de su vecindario llaman de San Juan y hasta donde habrá once o doce leguas, teniendo de ancho de norte a sur cuatro a cinco leguas de orilla a orilla según el paraje por donde se mide. Que dichas lagunas toman sus crecientes mayores desde el mes de octubre, hasta el mes de enero, que es cuando se derriten las nieves de la Sierra [...] y que por esta misma razón crece el nominado río que sale de las Lagunas y prosigue hasta más abajo de la capilla de San Miguel, que no sabe cuántas leguas, pero si que se desparrama en otros muchos bañados, y Lagunas que prosiguen encadenándose hasta el Desaguadero a excepción de algunos años en que suelen no alcanzar las aguas al paraje de Las Quijadas en

82 Vignati, 1953: 72.

83 De noroeste a sureste, en el paraje de Capilla del Rosario: el alcalde pedáneo Feliciano Díaz, el capitán de milicias Ramón Videla, y los sargentos Francisco Jufré y Mateo Pizarro; en Las Playas, el alcalde Miguel Durán y el capitán Martín Chay; en Los Chomes, el teniente de milicias Luis Montoya y en el Alto Grande, ya a ocho leguas de Desaguadero, el alcalde Ángel Acevedo. 
la estación del verano, y que por esta razón no sabe si se podrá dar agua permanente al Desaguadero ${ }^{84}$

Díaz agregó que "por la baquía que tiene de aquellos parajes" sabe que no podrá lograrse que las aguas corran en forma permanente en un cauce debido a lo guadaloso del terreno, que obligaría a una limpieza continua de los canales o cortes de "las muchas arenas y lodos que allí conducen las aguas llovedizas". 85

Tanto Díaz como el Sargento Mateo Pizarro, los prácticos que más información aportaron en Lagunas del Rosario, manifestaron también que la principal causa que estaba mermando las aguas era que "con las muchas [aguas] que sacan para el riego de Mendoza [estas] aminoran y se cortan como a diez leguas antes de la entrada". ${ }^{86}$ Los inmensos caudales estaban ya efectivamente en retroceso y los prácticos señalaban por primera vez un proceso que concluiría con el desecamiento de las lagunas en el siglo XX.

Al contrario que los habitantes de las lagunas del Rosario, los entrevistados de aquellas más próximas al Desaguadero desalentaron el proyecto y recomendaron en cambio la realización de aljibes alimentados por agua de lluvia, no del río. La principal causa era que antes de la laguna de las Quijadas el río atravesaba otras que rodeaban grandes salinas, por lo que el agua del Desaguadero corría salada a partir de dicho punto, aunque los naturales la consumieran. ${ }^{87}$ Asimismo, consideraron difícil proveer agua de riego para sembrar en Corocorto a raíz de que el río corría muy encajonado a esa altura, por lo que el nivel del agua no permitía su extracción mediante canales para extraerla. Esta razón era la misma que hizo escribir a Amigorena que, en caso de realizar aljibes a lo largo del Desaguadero, deberían ser llenados con "una máquina dispuesta al intento."

Como hemos visto los naturales se habían replegado hacia las lagunas debido al acoso de los indígenas alzados y los españoles habían propuesto que se nuclearan en la villa en torno de la capilla de San José de Corocorto. Pese a ello, los entrevistados confirmaron que luego de fundarse la Villa, sus habitantes habían ido a parar a las lagunas por causa de los indios no sometidos: "siempre que tenía agua este río, solían entrar

84 Vignati, 1953: 61.

85 Vignati, 1953: 62.

86 Vignati, 1953: 63.

87 Vignati, 1953: 68-69. 
los indios por sus orillas [...] que esta fue la causa por las que él y otros abandonasen sus babitaciones y se internasen a estos parajes". ${ }^{88}$ Pese a los informes obtenidos Amigorena persistió en recomendar la realización de las obras para mantener el curso permanente del Desaguadero seguramente por sus objetivos geopolíticos o por desconfianza en las sugerencias locales. En cuanto a los intereses de los indígenas, los de las lagunas del Rosario temían que baje el nivel de las lagunas y se vea afectada la capacidad pesquera. En cuanto a los de las lagunas orientales, estos rechazaban evidentemente la idea por miedo a que favoreciera la introducción de los indios alzados. Pero también, como insinúa Amigorena, porque las salinas eran uno de los principales recursos económicos locales y la canalización del río secaría las lagunas que las rodeaban de donde debían ser regadas por canales para que la sal "se crie y reproduzca". 89

Para Amigorena estaba claro que fijar la frontera con los indígenas alzados era un objetivo principal y eso debía lograrse con la erección de un fuerte en Corocorto. Finalmente fue autorizado a erigir el fuerte y la villa trayendo "todos los indios que habitan a orillas de las Lagunas desde la Capilla de San Miguel hacia abajo (es decir exceptuando los del Rosario y Asunción)". ${ }^{90}$ El maestre de campo puso mucho empeño en esta obra, que desarrollaría en 1791 refundando como hemos visto la villa de San José de Corocorto. Sin embargo, pese a este nuevo acto fundacional la asignación de las parcelas y entrega de las tierras siguió sin concretarse. En febrero de 1810 el ayudante mayor de las milicias urbanas Pedro Vargas solicitaba el cabildo de Mendoza formalizar la fundación de la Villa "Ordenada hace más de 50 años por el gobierno de esta provincia y junta de población". ${ }^{91}$ Y en 1813 los vecinos del partido de Corocorto todavía pedían la confección de un plano topográfico, la delimitación de la villa y la entrega de los títulos de propiedad para que "podamos trabajar". Recién en 1850 las tierras de la villa serían expropiadas por el estado provincial para fundar la Villa de La Paz y el departamento del mismo nombre. La temida amenaza fronteriza, sin embargo, no desaparecería y los ataques de pampas y ranqueles a la villa y su entorno serían una

88 Vignati, 1953: 61, 70.

89 Vignati, 1953: 78.

90 Vignati, 1953: 81.

91 AHM, independiente, carp. 1, doc. 1.

92 AHM, independiente, carp. 1, doc. 2. 
realidad cotidiana hasta la década de 1870, siendo arrasada por un ejército ranquel en 1868.

Como vimos, entonces, las fundaciones de villas y establecimiento de pueblos de indios en Corocorto y las Lagunas durante la segunda mitad del siglo XVIII fueron condicionadas por una dinámica previa de asignación y defensa de derechos de tierras indígenas otorgados por las necesidades militares de los españoles desde fines del siglo XVII y principios del XVIII, con la reducción de los chiquillanes y otras parcialidades puelches. Avanzado el siglo, estos indígenas incorporados que aún mantenían territorios con relativa autonomía fueron revalorizados nuevamente como presencia militar defensiva para contener un retroceso de la frontera sur y sureste de Cuyo. Estos grupos se desplazaban según la época y las condiciones políticas (presión española o de indígenas del sur) entre Corocorto y el río Desaguadero y las lagunas de Guanacache. Durante el proceso fundacional pudieron negociar las características de los proyectos desarrollados por los españoles para la línea defensiva que involucraban una reingeniería hídrica que los perjudicaba al mismo tiempo que sugerir a los españoles estrategias apropiadas. Finalmente, las poblaciones de Corocorto y las Lagunas eran igual y mayoritariamente indígenas pero estas últimas mantuvieron hasta el siglo XIX una autonomía mucho mayorque Corocorto, junto a la cual terminó consolidandose la via comercial terrestre entre Mendoza y Buenos Aires.

\section{Conclusión}

A lo largo de este artículo hemos podido apreciar que en Cuyo grupos indígenas incorporados al dominio colonial poseyeron tierras reconocidas por la corona española bajo la forma de reducciones y pueblos, defendieron sus derechos a las mismas hasta fines del período colonial e incluso poblaron las villas teóricamente de españoles hasta principios del siglo XIX. Esto desmiente categóricamente tanto las narrativas de extinción de los indios de la región como la idea igualmente instalada de su desestructuración étnica o la falta de liderazgos étnicos desde los primeros tiempos coloniales. 
A su vez, exploré la hipótesis de que las relaciones fronterizas de los españoles con los indígenas libres, pehuenches, puelches, aucas, huilliches, pampas y otras denominaciones relativas al "mundo mapuche" fueron decisivas para la dinámica de reconocimiento político y acceso territorial de los indígenas incorporados: huarpes, y parte de los chiquillanes y sus descendientes, y tal vez yacampis o capayanes/diaguitas. Concretamente, que sus servicios militares fueron la clave para la obtención de derechos de tierras. En efecto entre fines del siglo XVII y principios del XVIII los españoles reconocieron la propiedad de tierras y los cargos de caciques a parcialidades clasificadas como huarpes y puelches en el centro y sur de la jurisdicción (como así también diaguitas en el norte) por sus necesidades estratégicas en relación con la presión de puelches, pehuenches, pampas y ranqueles en las fronteras sur y sureste. Esta constatación obliga a modificar las representaciones que se han hecho de la frontera sur de Mendoza como un límite interétnico entre indios del "mundo mapuche" y criollos o españoles, para incorporar una dimensión multiétnica al interior del territorio de supuesto dominio colonial. Además, permitiría pensar la frontera sur como un territorio de relaciones políticas y sociales mucho más abarcativas que los frentes de expansión o retroceso colonial, con distintas realidades y grados de dominio territorial por parte de diversos actores indígenas que incluyen por lo menos al área de Guanacache.

Tomando las prácticas y argumentos de los caciques y otras autoridades indígenas como alcaldes, prácticos y oficiales de milicias a lo largo del siglo XVIII y especialmente en la segunda mitad, podemos concluir también que la negociación de sus servicios militares e incluso la permanencia en algunos territorios fue más que una imposición española la estrategia de los indígenas "incorporados" al territorio colonial para obtener o mantener sus tierras y poder político. El control territorial que se hace evidente poseían en las Lagunas, obligó a los españoles a negociar con ellos la fundación y ubicación de los pueblos y villas que se encaró como un vasto proyecto tardo colonial en la segunda mitad del siglo XVIII, e inclusive a limitar parte la estrategia defensiva colonial en el área en lo que respecta a la alteración de la infraestructura hídrica. En retrospectiva, entonces, la instalación de pueblos y villas parece haber servido menos a los españoles y autoridades criollas para establecer un control sobre los indígenas que a estos para mantener o reforzar legalmente el arraigo 


\section{\begin{tabular}{l|l} 
D. Escolar & 26/27: pp. 9-39
\end{tabular}

sobre sus tierras, generando antecedentes que serían utilizados estratégicamente con posterioridad para su defensa judicial. Este reconocimiento de derechos y el estatus reduccional fue la base principal de los argumentos legales para resistir el despojo de sus tierras a lo largo de los siglos XVIII y XIX hasta avanzado el período independiente $\mathrm{y}$, en forma menos visible, incluso hasta la actualidad. 


\section{FUENTES}

\section{Éditas}

Bialet Massé, J. 1985, Informe sobre el Estado de las Clases Obreras Argentinas a Comienzos de Siglo, CEAL, Buenos Aires.

Espejo, J. L. 1954, La provincia de Cuyo del reino de Chile, Fondo Histórico y Bibliográfico José Toribio Medina/ Imprenta Universitaria, Santiago de Chile.

Vignati, M. A. 1953, “Aportes al conocimiento antropológico de la Provincia de Mendoza III. Diario de viaje por las Lagunas en el año de 1789" en Notas del Museo de Eva Perón, XVI, 57, pp. 51 a 103.

\section{Inéditas}

Archivo General de Indias

Archivo Histórico de Mendoza

Archivo Histórico de San Juan

Archivo Nacional de Chile

\section{BIBLIOGRAFÍA}

Amselle, J. L. 1998, Mestizo Logics. Anthropology of identity in Africa and Elsewhere, Stanford University Press.

Barth, F. 1976, Los grupos étnicos y sus fronteras, Fondo de Cultura Económica, México.

Boccara, G. 2007, Los vencedores: Historia del pueblo mapuche en la época colonial, Universidad Católica del Norte, San Pedro de Atacama.

Canals Frau, S. 1946, "Etnología de los huarpes. Una síntesis" en Anales del Instituto de Etnología Americana, 7, pp. 9 a 149.

Cueto, A. O. 1989, "La legislación hispánica sobre tierras y su vigencia en la Mendoza colonial (siglos XVI-XIX)" en Revista de Estudios Regionales, 3, pp. 65 a 108.

Escolar, D. 2007, Los Dones étnicos de la Nación. Identidades huarpes y modos de producción de soberania en Argentina, Prometeo, Buenos Aires.

Escolar, D. 2020a, "Mitologías soberanas: tierras indígenas y construcción de la propiedad privada en Mendoza a fines del siglo XIX" en Memoria Americana. Cuadernos de Etnohistoria, 28, 1, pp. 92 a 116.

Escolar, D. 2020b, “Los 'últimos caciques' de Cuyo. Tierras, política y memorias indígenas en la Argentina criolla (Mogna, siglos XVII-
XIX)" en Revista del Museo de Antropología 13, 2, pp. 215 a 230.

Jara, A. 1958, "Importación de trabajadores indígenas en el siglo XVII" en Revista Chilena de Historia y Geografia, 124, pp. 175 a 212.

Michieli, C. T. 2000, La disolución de la categoría jurídico-social de «indio» en el siglo XVIII: El caso de San Juan (Región de Cuyo), Universidad Nacional de San Juan/ Facultad de Filosofía Humanidades y Artes/ Instituto de Investigaciones Arqueológicas y Museo, San Juan.

Michieli, C. T. 1992, “Tráfico transcordillerano de ganado y la acción de los indígenas cuyanos en el siglo XVII" en Publicaciones del Instituto de Investigaciones Arqueológicas y Museo UNSJ, 19, pp. 21 a 47.

Morales Guiñazú, F. 1938, Primitivos Habitantes de Mendoza (Huarpes, Puelches, Pehuenches, Aucas, su lucha, su desaparición), Best Hermanos, Mendoza.

Nacuzzi, L. R. 1998, Identidades impuestas: tehuelches, aucas y pampas en el norte de la Patagonia. Sociedad Argentina de Antropología, Buenos Aires.

Prieto, M. de R. 2000, "Formación y consolidación de una sociedad de frontera en un área marginal del Reino de Chile: La provincia de Cuyo en el siglo XVII" en Anales de Arqueología y Etnología, 52-53.

Prieto, M. del R. 1976, "El proceso de aculturación de los huarpes de Mendoza" en Anales de Arqueología y Etnología XXIX-XXXI, , pp. 237 a 272.

Sosa Morales, N. 1965, El muy magnífico señor Don José Francisco de Amigorena (Cuyo durante la intendencia de Córdoba), s.e.

Torre Revelo, J. 1946, El Marqués de Sobremonte, Gobernador intendente de Córdoba y Virrey del Río de la Plata. Ensayo Histórico. Publicaciones del Instituto de Investigaciones Históricas, Facultad de Filosofías y Letras, Buenos Aires.

Verdaguer, J. A. 1931, Historia eclesiástica de Cuyo (I), Premiata Scuola Tipográfica Salesiana, Milano. 